https://helda.helsinki.fi

Growth of Human Pluripotent Stem Cells Using Functional Human Extracellular Matrix : Human Embryonic Stem Cell Protocols

\title{
Sanz-Garcia, Andres
}

SPRINGER NEW YORK LLC

2016

Sanz-Garcia , A , Stojkovic , M \& Escobedo-Lucea , C 2016 , Growth of Human Pluripotent Stem Cells Using Functional Human Extracellular Matrix : Human Embryonic Stem Cell Protocols . in K Turksen (ed.), Human Embryonic Stem Cell Protocols . vol. 1307 , Methods in Molecular Biology , no. 1307 , SPRINGER NEW YORK LLC , New York , pp. 39-60 . https://doi.org/10.1007/7651

http://hdl.handle.net/10138/163073

https://doi.org/10.1007/7651_2014_154

unspecified

acceptedVersion

Downloaded from Helda, University of Helsinki institutional repository.

This is an electronic reprint of the original article.

This reprint may differ from the original in pagination and typographic detail.

Please cite the original version. 
$1 \quad$ Growth of Human Pluripotent Stem Cells using

1. Tissue Engineering Group. Division of Pharmaceutical Biosciences, Faculty of Pharmacy,

7 University of Helsinki, Finland

8 2. Institute of Advanced Biomedical Engineering and Science, Tokyo Women's Medical

9 University TWINS. Tokyo, Japan

10 3. SPEBO Medical, Leskovac, Serbia

11 4. Department of Human Genetics, Faculty of Medicine, University of Kragujevac, Serbia

Correspondence: Carmen Escobedo-Lucea, $P h D$

1 Tissue Engineering Group. Centre of Drug Research (CDR). Division of Pharmaceutical Biosciences. Faculty of Pharmacy. .University of Helsinki, Viikinkaari 5 E (P.O. Box 56), 00014 Helsinki, Finland 2 Institute of Advanced Biomedical Engineering and Science. Tokyo Women's Medical University TWINS. 8-1 Kawada-cho, Shinjuku-ku, Tokyo 162-8666, Japan carmen.escobedo-lucea@,helsinki.fi

\section{The final publication is available at link.springer.com Human Embryonic Stem Cell Protocols} http://link.springer.com/protocol/10.1007/7651_2014_154 


\section{Abstract}

39 The use of animal products in the derivation and maintenance of human pluripotent stem cells

40 (hPSCs) limits their possible applications in research and in clinics. Thus, one of the major goals

41 in regenerative medicine is the establishment of animal-free conditions to support the culture and

42 differentiation of human stem cells. Human fibroblasts produce an extracellular matrix (ECM)

43 which can be extracted without the use of detergents, sterilized, and then used to coat tissue

44 culture plates.

45 We have shown that human embryonic stem cells (hESCs) grown on this matrix maintain their

46 pluripotency in the presence of medium conditioned by fibroblast cells, and that these cells

47 maintain expression of surface proteins (SSEA4, Tra1-60, Tra1-81), alkaline phosphatase activity

48 and specific intracellular markers (Nanog, Oct-4, Tert, FoxD3) in hESCs. This growth system

49 reduces exposure of hPSCs to feeder layers and animal ingredients, thereby limiting the risk of

50 pathogenic contamination and additionally, facilitating their manipulation. Herein we present an

51 improved version of our previous protocol for extracting ECM from human foreskin fibroblast

52 using a different buffer. Our new hypotonic shock method is detergent-free, reduces costs, and

53 preserves the integrity of the extracted ECM. This improved protocol has been validated for

54 undifferentiated-state hPSC maintenance (more than 40 passages), stem cell differentiation and

55 for cell migration assays.

57 Keywords: human embryonic stem cells; human pluripotent stem cells, in vitro growth; 58 extracellular matrix, hypo-osmotic lysis buffer 


\section{1. Introduction}

62 The stem cell biology field is continually transforming, especially in recent years with the

63 introduction of several validated protocols for obtaining human-induced pluripotent stem cells 64 (hiPSCs) (1,2), which have created new avenues for studying different diseases and regenerative medicine applications. Several human embryonic stem cell (hESC) and hIPSC lines have been derived and grown using mouse feeder layers, Matrigel ${ }^{\circledR}$, or other animal reagents $(3,4)$. However, recent successes using pluripotent stem cell (PSC) derivatives in clinical trials $(\mathbf{5 , 6})$ have emphasized the need for improved quality standards before these derivatives are applied in cell therapies. In particular, new culture methods must be developed that circumvent the need for animal products because these might provoke infections or immune rejection following transplantation into patients (7). Thus, chemically defined culture systems that are devoid of nonhuman substances will greatly facilitate the use of human stem cells (hSCs) in therapies.

Extracellular matrix (ECM) modulates cellular adhesion processes and signaling inside stem cell niches and is essential for maintaining their structure and supportive qualities $(\mathbf{8 , 9 )}$. An attractive alternative to the use of feeder cells, and the complications associated with them, is the development of an animal-free ECM, and there would be many advantages to maintaining PSCs on such supports. Indeed, undefined mixtures of natural and synthetic matrix proteins are already used as a coating for in vitro human stem cell culture (10), but unfortunately, most of these reagents are cost-prohibitive for many laboratories. Decellularization procedures are traditionally used to isolate ECM from cells and organs (11), facilitating remodeling in animal models and humans. However, the procedures used to remove the cells, especially detergent-based methods, can alter the native structure of the $\operatorname{ECM}(12,13)$.

83 We previously published a protocol which allows long-term growth of undifferentiated hESCs on 84 human functional foreskin ECM (hffECM), extracted by using RIPA buffer and cultured using 85 human foreskin conditioned medium, in the Methods in Molecular Biology series (14). Here we present a modification of our previous protocol which replaces RIPA with a simple, low-cost hypotonic buffer without detergents. The hffECM obtained is capable of maintaining the pluripotency of hESCs for more than 40 passages (12). Additionally, our hffECM has also been validated as a coating for directed-differentiation experiments by using both hESCs and mesenchymal stem cells (MSCs) and as a basis for cell migration studies $(\mathbf{1 2 , 1 5 , 1 6 )}$.

\section{2. Materials}


2.1. Culture of Human Foreskin Fibroblast for Derivation of Conditioned Media and Human

Functional Foreskin-derived Extracellular Matrix (hffECM)

1. Human foreskin fibroblasts (ATCC, Catalogue No. CRL-2429, Passages 11--18; see Note 1).

2. Iscove's medium (Sigma, St. Louis, MO), supplemented with 10\% human serum (HS), 1\%

Glutamax (GIBCO, Invitrogen, Carlsbad, CA).

3. Gelatin (1.5\%; Sigma). In a sterile bottle, add embryo-tested water (Sigma) to gelatin. Warm the mixture to $37^{\circ} \mathrm{C}$ in a water bath using a shaker. Store at $4^{\circ} \mathrm{C}$ or make aliquots and keep them frozen at $-20^{\circ} \mathrm{C}$. These aliquots can be stored for up to 6 months. Before proceeding with tissue culture, thaw the aliquots and dilute them to $0.01 \%$ with sterile Dulbecco's PBS (DPBS) (Invitrogen). Pass the solution through a $0.22 \mu \mathrm{m}$ filter (Nalgene, Hereford, UK). Coat the culture surfaces by pipetting $1 \mathrm{~mL} /$ well into 6-well plates (BD, San Jose, CA) or $12 \mathrm{~mL}$ into a $75 \mathrm{~cm}^{2}$ flask (Iwaki, Ibaraki, Japan). Allow the gelatin to settle at $37^{\circ} \mathrm{C}$ for $30 \mathrm{~min}$. Plates may be used immediately or stored at $4^{\circ} \mathrm{C}$ to prevent evaporation.

4. Mitomycin C (Fluka, Buchs, Switzerland) is dissolved in Iscove's medium (Sigma) at 1 $\mathrm{mg} / \mathrm{mL}$, stored at $4^{\circ} \mathrm{C}$ and then added to the cultures as required.

5. Triple Select (GIBCO, Invitrogen) is used instead of trypsin to detach cells from the tissue culture plates.

111 7. Trypan Blue (Sigma) to count and evaluate cell viability (see Note 2).

112 8. Neubauer haemocytometer (Brand, Wertheim, Germany).

\section{2.2. Derivation of Conditioned Media}

114 As previously described (17), TESR1 medium is usually used as the base media for human

115 foreskin fibroblast conditioning, using passage 11 to 18 cells.

116 1. TERS1 conditioned media: after collection media can be frozen at $-80^{\circ} \mathrm{C}$ for up to 6 months

117 (see Notes 3 and 4).

\section{2.3. Preparation of Human Functional Foreskin-derived Extracellular Matrix (hffECM)}

119 1. Osmotic lysis buffer Tris-EDTA (TE) pH 7.4: 10mM TrisHCl pH 7.4, 1mM EDTA pH 8 (all

120 from Sigma). For preparation details see Note 5.

121 2. Cell scrapers (Falcon, BD Biosciences, Madrid).

122 3. DPBS (GIBCO, Invitrogen).

123 2.4. Preparation of Samples for Transmission Electron Microscopy (TEM)

124 1. PB (EMS). 
125 2. Glutaraldehyde (3\%): dilute glutaraldehyde (Electron Microscopy Science [EMS], Hattfield,

126 PA) from a $25 \%(\mathrm{v} / \mathrm{v})$ stock in PB.

127 3. Petri dish (Falcon, BD).

128 4. Disposable Pasteur pipettes (Falcon).

129 5. Osmium 1\% (Sigma): prepared by diluting osmium in PB.

130 6. Uranyl acetate (2\%) diluted in $70 \%$ ethanol.

131 7. Preparation of alcohol gradient: use the appropriate volume of absolute ethanol (Merck), mixed

132 with distilled water to prepare $30 \%, 50 \%, 70 \%$, and $90 \%$ ethanol solutions.

133 8. Resin LR-White (EMS).

134 See Note 6 for safety measures that must be adopted to perform this technique.

135 2.5. Preparation of Samples for Atomic Force Microscopy (AFM)

136 1. $0.1 \mathrm{M}$ PBS (Gibco)

137 2. 2\% paraformaldehyde/2.5\% glutaraldehyde/PB (all from EMS).

138 3. Series of ethanol/water solutions (30\%, 50\%, 70\%, 90\%, 96\%). All from Sigma.

139 4. Absolute ethanol (Sigma).

140 2.6. Culture and Maintenance of Undifferentiated hESC lines

141 1. H9 and H1 hESC lines (WiCell, Madison, WI).

142 2. TERS1 conditioned media.

143 3. TGF- $\beta 1$ (Invitrogen): reconstituted with sterile $4 \mathrm{mM} \mathrm{HCl}$ (Sigma) containing $1 \mathrm{mg} / \mathrm{mL}$ of

144 human serum albumin (Sigma) to a final stock solution concentration of $40 \mathrm{ng} / \mathrm{mL}$. Store in 50

$145 \mu \mathrm{L}$ aliquots at $-20^{\circ} \mathrm{C}$.

146 4. Human recombinant basic fibroblast growth factor (bFGF; Invitrogen) is dissolved in $1 \mathrm{~mL}$

147 DMEM Knockout Medium (Invitrogen) and stored in $100 \mu \mathrm{L}$ aliquots at $-20^{\circ} \mathrm{C}$.

$148 \quad$ 2.7. Analysis of Undifferentiated hESC Markers

149 2.7.1. Staining of Pluripotency Cell Surface Markers by Immunocytochemistry

150 Antibodies that detect specific cell-surface hESC markers are commercially available from

151 Chemicon and antibodies for detection of the ECM component fibronectin are available from

152 Sigma. Secondary antibodies are all commercially available from Invitrogen. See Tables 1 and 2

153 for recommended dilutions and providers.

154 1. DPBS without $\mathrm{Ca}^{2+}, \mathrm{Mg}^{2+}$ (GIBCO, Invitrogen).

155 2. 4\% paraformaldehyde (see recipe at 2.7.2.2).

156 3. $0.05 \%$ sodium azide (Sigma) in DPBS. 
4. Triton-X-100 (Sigma): prepare a dilution of 1\% Triton-X-100 in DPBS to permeabilize the hESCs.

5. Blocking solution: 4\% serum in DPBS. Serum for the blocking solution should be of the same origin/animal as the secondary antibody.

6. Prolong gold anti-fade reagent with DAPI (Invitrogen). See Note 7.

1. This kit provides two components for AP detection: Fast Red Violet solution $(0.8 \mathrm{~g} / \mathrm{L}$ stock $)$ and naphthol AS-BI phosphate solution (4 mg/mL) in AMPD buffer ( $2 \mathrm{~mol} / \mathrm{L}), \mathrm{pH} 9.5$.

2. Paraformaldehyde 4\% in PBS: Prepared fresh with distilled water. To prepare $100 \mathrm{~mL}$, heat 50 $\mathrm{mL}$ distilled water to $60^{\circ} \mathrm{C}$ on a hot plate in a fume hood (do not exceed $65^{\circ} \mathrm{C}$ ) and add $4 \mathrm{~g}$ of paraformaldehyde powder. Stir the solution until it becomes clear (a few drops of $\mathrm{NaOH}$ can be added). After that, filter the solution through a $0.22 \mu \mathrm{m}$ filter and add $50 \mathrm{~mL}$ of sterile PBS at $\mathrm{pH}$ 7.4 (see Note 8).

3. TBST $1 \times$ Rinse Buffer: prepared fresh with $20 \mathrm{mM}$ Tris- $\mathrm{HCl}, \mathrm{pH} 7.4,0.15 \mathrm{M} \mathrm{NaCl}, 0.05 \%$

171 Tween-20 (all from Sigma).

\subsubsection{Intracellular Markers by RT-PCR and QPCR Analysis}

173 See Table 3 for the complete list of primers and reaction conditions.

174 1. RNeasy mini kit (74104, Qiagen).

175 2. Deoxyribonuclease (DNase) I (RNasa-free DNase SET; 79254; Qiagen).

176 3. High Capacity cDNA RT kit (PN 4368814; Applied Biosystems).

177 4. FastStart PCR Master (04710436001; Roche).

178 5. Power SYBR® Green PCR master mix (4367659; Applied Biosystems).

179 6. PCR microplates.

$1807.1 .5 \mathrm{~mL}$ sterile microcentrifuge tubes (Eppendorf, Hamburg, Germany).

181 8. Absolute ethanol (Merck, Darmstadt, Germany).

182 9. Standard table-top microcentrifuge capable of $13,000 \times \mathrm{g}$ centrifugal force.

183 10. Standard thermal cycler.

184 11. NanoDrop spectrophotometer or similar to evaluate the synthetized cDNA quality.

185 2.7.4. Telomerase Activity

186 1. TRAPEZE Telomerase Detection Kit (Chemicon, Billerica, MA).

187 2. PBS without $\mathrm{Ca} 2+, \mathrm{Mg} 2+(\mathrm{GIBCO})$.

188 3. 10--20\% nondenaturing polyacrylamide precasted gels.

189 4. 10× TBE (BioRad, Hercules, CA). 
5. SYBR green (Molecular Probes).

191 6. Loading buffer 10× (BioRad).

192 7. Nondenaturing 10--20\% polyacrylamide gel (15\% precasted gels from BioRad).

\section{Methods}

195 Extracellular matrix compounds play important roles in cell adhesion, attachment, cell interactions, and proliferation $(\mathbf{1 8 , 1 1 )}$. Previous studies have demonstrated that the components of ECM support undifferentiated growth of hESCs. Extracellular matrix is generally organized into a three-dimensional fibrous structure and therefore, it is crucial to extract the ECM samples from human fibroblasts rapidly and at $4^{\circ} \mathrm{C}$ which prevents conformational changes and protein degradation. Transmission electron microscopy (TEM) and AFM can be used to assess the integrity of hffECM after the obtention. To validate functionality, it is very important to evaluate the ability of the extracted ECM to maintain hESCs in the undifferentiated state. This can be assessed by long-term growth of hESCs on this ECM and by routine analysis of pluripotency using the following assays: RT-PCR, immunocytochemistry, determination of alkaline phosphatase, and telomerase expression and analysis of spontaneous differentiation ability (19).

\subsection{Preparation of Fibroblast Cells and Conditioned Media}

1. Human foreskin fibroblasts are grown in Iscove's Medium and the cells are split using Triple Select every 5--7 days.

2. When confluent, the cells were inactivated using mitomycin $\mathrm{C}$ at $37^{\circ} \mathrm{C}$ in an incubator with $5 \%$ $\mathrm{CO}_{2}$ for $3 \mathrm{~h}$.

3. They are then washed with DPBS three times ( $5 \mathrm{~min}$ ), digested, and counted (see Note 2).

4. Seed fibroblast at a density of $6 \times 10^{6}$ cells in a T75 flask coated with $0.1 \%$ gelatine, and culture at $37^{\circ} \mathrm{C}$ with $5 \% \mathrm{CO}_{2}$ for $24 \mathrm{~h}$ before adding TERS1 medium.

5. TERS 1 conditioned medium is collected every day until day 7 , and stored at $-80^{\circ} \mathrm{C}$ for up to 6 months (see Notes 3 and 4).

\subsection{Preparation of Extracellular Matrix (ECM)}

217 1. Human foreskin fibroblasts are grown in an appropriate medium and the cells are split using

218 Triple-select every 5--7 days. When the cells reach 100\% confluence, they are inactivated by

219 treatment with mitomycin $\mathrm{C}(10 \mu \mathrm{g} / \mathrm{mL})$ for $3 \mathrm{~h}$, and then washed three times with DPBS.

220 2. Cells are detached, counted and seeded $\left(2 \times 10^{5}\right.$ cells/per well $)$ in a six-well plates, coated with

$2210.1 \%$ gelatin, and cultured at $37^{\circ} \mathrm{C}$ and $5 \% \mathrm{CO}_{2}$ for $24 \mathrm{~h}$.

222 3. Inactivated cell cultures are maintained for 7--8 days, with a media change every second day. DOI 10.1007/7651_2014_154 
4. Foreskin cultures are treated on day 7, following the recommendations described in (15).

5.Cells are washed twice with DPBS without $\mathrm{Ca}^{2+}$ and $\mathrm{Mg}^{2+}$ and subsequently lysed by osmotic shock with Tris EDTA buffer (10 mM Tris, 1 mM EDTA, PH 7.4) adding, $1.5 \mathrm{~mL}$ per $10^{6}$ cells.

6. After addition of osmotic shock buffer, cells are incubated o.n. at $4{ }^{\circ} \mathrm{C}$ using an orbital shaker, after which time the Tris-EDTA buffer is removed by aspiration (see Note 9).

6. Lysed cells are eliminated from the plates by rinsing six times ( 5 min each) with DPBS. Plates containing the remaining hffECM are stored at $4^{\circ} \mathrm{C}$ or dried and sterilised using standard methods. Examples of foreskin fibroblast cells and ECM samples studied using TEM are shown in Fig. 1A.

\subsection{Preparation of Samples for TEM (see Notes 6 and 10 when Planning these Experiments)}

1. Wash samples twice with PBS for 2--3 min.

2. Fix for $30 \mathrm{~min}$ at $37^{\circ} \mathrm{C}$ with $3 \%$ glutaraldehyde. Add glutaraldehyde carefully until the plate surface is totally covered.

3. Incubate for $30 \mathrm{~min}$ and store at $37^{\circ} \mathrm{C}$, keeping the samples inside a box or Petri dish to avoid release of carcinogenic vapor.

4. Aspirate glutaraldehyde with a disposable Pasteur pipette and discard adequately.

5. Wash 3--4 times for 3 min with PBS.

6. Cover the samples with PBS and maintain them at $4^{\circ} \mathrm{C}$ (see Note 11).

7. Fixation and contrasting: add $1 \mathrm{~mL}$ of $2 \%$ osmium to cover the plates and leave for $1 \mathrm{~h}$.

8. Wash three times (5 min each) with distilled water at $4^{\circ} \mathrm{C}$ (do not exceed $15 \mathrm{~min}$ ).

9. Dehydration procedure (all steps are performed at $4^{\circ} \mathrm{C}$ ):

\subsection{Add $30 \%$ alcohol for $5 \mathrm{~min}$.}

9.2. Wash with $50 \%$ alcohol $(10 \mathrm{~min})$ at $4^{\circ} \mathrm{C}$ (exceeding this time can cause protein damage).

\subsection{Wash twice with $70 \%$ alcohol (10 $\mathrm{min}$ each).}

10. Add $1 \mathrm{~mL}$ of $2 \%$ uranyl acetate in $70 \%$ alcohol and incubate for $2 \mathrm{~h}$ at $4{ }^{\circ} \mathrm{C}$.

11. Continue with the dehydration process by using the following alcohol gradient:

11.1 Add 70\% ethanol 2 times $\times(10 \mathrm{~min}$ each $)$.

11.2. Wash with $90 \%$ ethanol 2 times $\times(10 \mathrm{~min}$ each $)$.

12.1. Incubate in 2 parts $90 \%$ ethanol: 1 part resin for $45 \mathrm{~min}$ at RT.

12.2. Replace the mixture using a Pasteur pipette and discard adequately. 
12.3. Prepare a dilution 1part 90\% ethanol: 2 parts resin, add to the samples and incubate for $45 \mathrm{~min}$. shaker.

263 14. Detach and proceed with the sectioning.

264 15. Observe the samples under a transmission electron microscope.

\subsection{Atomic Force Microscopy (AFM)}

AFM provides detailed 3-dimensional images of ECM protein-surface interactions.

1. Samples should be washed in $0.1 \mathrm{M}$ PBS and fixed in $2 \%$ paraformaldehyde $/ 2.5 \%$ glutaraldehyde/PB for $1 \mathrm{~h}$ at room temperature.

3. Samples are dehydrated using a series of ethanol/water solutions $(30 \%, 50 \%, 70 \%, 90 \%$, and 96\%) for 10 min with final dehydration in absolute ethanol for 10 min twice.

3. The dehydrated samples were examined by AFM, operating in the tapped-air mode.

4. The ECM protein distribution (on glass) is estimated from AFM images. The amplitude set point should be $1.3 \mathrm{~V}$ with a drive amplitude of $300 \mathrm{mV}$.

5. Surface roughness is calculated by processing 10 representative AFM images. Images of glass surfaces with and without hffECM captured using AFM are shown in Fig. 1B.

1. Once the ECM-coated plates are ready for use, conditioned medium which has been collected,

278 should be added.

279 2. Add $2 \mathrm{~mL}$ of conditioned media containing $50 \mathrm{ng} / \mathrm{mL}$ and $100 \mathrm{ng} / \mathrm{mL}$ of fresh TGF- $\beta 1$ and

280 bFGF, respectively. Place the 6-well plates in an incubator at $37^{\circ} \mathrm{C}$ with $5 \% \mathrm{CO}_{2}$ for at least $3 \mathrm{~h}$

281 before seeding the new hESC colonies.

282 3. Wash the hESC colonies maintained on human feeders twice with prewarmed DMEM 283 medium.

284 4. Dissect hESC colonies mechanically and collect them in a $15 \mathrm{~mL}$ polypropylene tube (see 285 Notes 12and 13).

286 5. Centrifuge the cells for $3 \mathrm{~min}$ at $200 \times \mathrm{g}$ and remove the supernatant.

287 6. Gently resuspend the pellet in conditioned medium supplemented with fresh TGF- $\$ 1$ and 288 bFGF in the same $15 \mathrm{~mL}$ tube. 
7. Add $1 \mathrm{~mL}$ of media containing 10--20 colonies to each well of the ECM-coated plates.

290 8. Incubate the plates at $37^{\circ} \mathrm{C}$ with $5 \% \mathrm{CO}_{2}$ and change the media every second day.

9. Undifferentiated hESCs should be transferred to new plates every 5--7 days and maintained at

$29237^{\circ} \mathrm{C}$ with $5 \% \mathrm{CO}_{2}$.

293 Examples of contrast phase microscope are shown in Fig. 2A and Fig. 2B.

\subsection{Detection of Cell Surface Pluripotency Markers by Immunocytochemistry}

295 1. Remove the culture medium.

296 2. Wash the cells once with DPBS without $\mathrm{Ca}^{2+}$ and $\mathrm{Mg}^{+}$. It is important to add the DPBS very

297 gently and not directly to the cells.

298 3. Fix hESCs in 4\% paraformaldehyde for $15 \mathrm{~min}$ at room temperature by adding $1.5 \mathrm{~mL} / \mathrm{well}$ to

299 the 6-well plates.

300 4. Wash 4 times with DPBS.

301 5. To permeabilize the hESCs, add $1.5 \mathrm{~mL}$ per well of $1 \%$ Triton-X-100, followed by an

302 incubation of $10 \mathrm{~min}$ at room temperature.

303 6. Wash twice (5 min each) with DPBS.

304 7. Apply 4\% of blocking solution at room temperature for $45 \mathrm{~min}$. Serum for the blocking

305 solution should be of the same species as the secondary antibody.

306 8. Remove the blocking solution but do not wash the cells.

307 9. Dilute the primary antibody blocking solution (see Table 1).

30810 . Add $1 \mathrm{~mL}$ of the corresponding primary antibody dilution to the cultures for at least $1 \mathrm{~h}$ at RT 309 or overnight at $4^{\circ} \mathrm{C}$.

310 11. Wash 3 times with DPBS. Cells can be left overnight before adding the secondary antibody.

311 12. Dilute the secondary antibody in DPBS and add $1 \mathrm{~mL}$ per well (see Table 2).

312 13. Incubate at room temperature for $60 \mathrm{~min}$ and in darkness as exposure to light may cause

313 bleaching of fluorescent labels.

314 14. Wash the cells 4 times with DPBS.

315 15. If the cells are attached to a coverslip mount it on a slide using prolong gold antifade reagent

316 with DAPI. Remove any bubbles that may have formed during mounting.

317 16. Let the slides dry for $15 \mathrm{~min}$ in conditions where they are protected from light.

318 17. After 90 min the samples can be observed using a fluorescence microscope. Examples of the

319 morphology and undifferentiated hESC surface markers grown on plastic dishes coated by ECM

320 derived from human fibroblasts and in the presence of conditioned medium are presented in Fig.

$321 \quad$ 2C,D and 3. 
Analyzes of mRNA expression by reverse transcription PCR (RT-PCR) and real-time quantitative PCR (QPCR) are carried out using standard protocols. An RT-PCR reaction is performed at $60^{\circ} \mathrm{C}$ and for 35 cycles, except for 32 -microglobulin (performed at $55^{\circ} \mathrm{C}$ for 35 cycles). The QPCR reaction is performed at $60^{\circ} \mathrm{C}(60 \mathrm{~s})$ and $95^{\circ} \mathrm{C}(15 \mathrm{~s})$ for 40 cycles. Primer sequences were designed using Primer3 software and synthesized by Sigma-Aldrich. All primer sequences and DNA fragments are listed in Table 3. Transcripts encoding the following proteins Oct-4, Tert, Nanog, and FoxD3 should be assessed for pluripotency, and AFP, DBH, and CAC for differentiation (specific lineage) markers. The B2-microglobulin gene is used as an

331 endogenous control (housekeeping) gene.

\subsubsection{Extraction and Quantification of Total RNA}

333 Total RNA extraction can be performed using $20 \mathrm{hESC}$ colonies maintained on ECM. As a

334 positive control, undifferentiated hESCs maintained on feeder cells should be used. We use the

335 RNeasy mini kit (74104; Qiagen) following provider-recommended instructions with some

336 modifications. To eliminate contamination by genomic DNA, the initial RNA pellet was

337 incubated with deoxyribonuclease (DNase) I (RNase-free DNase SET; 79254; Qiagen).

338 1. Cut the cells from the culture dish with a needle and collect them in a centrifuge tube.

339 2. Add $350 \mu \mathrm{L}$ of buffer RLT and vortex for $1 \mathrm{~min}$.

3403 . Centrifuge the lysate for $3 \mathrm{~min}$ at maximum speed. Carefully remove the supernatant by 341 pipetting out and discarding it.

342 4. Add 1 volume of $70 \%$ ethanol to the homogenized sample and mix well by pipetting only (do 343 not centrifuge). The volume might be less than $350 \mu \mathrm{L}$ due to loss during the homogenization

344 process. The use of ethanol can trigger precipitates to form; however, their presence has no 345 impact on the process.

346 5. Transfer up to $700 \mu \mathrm{L}$ from the sample, including any precipitates, to an RNeasay mini spin

347 column (pink) placed in a $2 \mathrm{~mL}$ collection tube, and close the lid.

348 6. Centrifuge at $8,000 \times g(10,000 \mathrm{rpm})$ for $15 \mathrm{~s}$, discard the flow-through and reuse the

349 collection tube for step 7. Note: if the sample volume is greater than $700 \mu \mathrm{L}$, the aliquots must be

350 centrifuged one after the other in the same column, discarding the flow-through after each

351 centrifugation.

352 7. Add $350 \mu \mathrm{L}$ RW1 buffer to the RNeasy mini spin column, close the lid, and centrifuge at 8,000

$353 x g(10,000 \mathrm{rpm})$ for $15 \mathrm{~s}$. Discard the flow-through and reuse the collection tube for step 10. 
354 8. Add $10 \mu \mathrm{L}$ DNase I stock solution to $70 \mu \mathrm{L}$ RDD buffer. Mix by gently inverting the tube;

355 centrifuge briefly to collect the liquid from the tube walls.

356 9. Add DNase I to the incubation mix $(80 \mu \mathrm{L})$ and transfer it directly to the RNeasy column

357 membrane, and it place on the benchtop at $20--30^{\circ} \mathrm{C}$ for $15 \mathrm{~min}$.

358 10. Add $350 \mu \mathrm{L}$ RW1 buffer to the RNeasy mini spin column, close the lid, and centrifuge at $\geq$

$3598,000 \times g$ for $15 \mathrm{~s}$. Discard the flow-through.

360 11. Add $500 \mu \mathrm{L}$ RPE buffer to the RNeasy mini spin column, close the lid, and centrifuge at $\geq$

$3618,000 \times g$ for $15 \mathrm{~s}$. Discard the flow-through and reuse the collection tube.

362 12. Add $500 \mu \mathrm{L}$ RPE buffer to the RNeasy mini spin column, close the lid, and centrifuge at $\geq$

$3638,000 x g$ for 2 min to wash the column membrane.

364 13. Place the RNeasy mini spin column in a new $2 \mathrm{~mL}$ collection tube and centrifuge at full speed

365 for $1 \mathrm{~min}$ to dry the membrane (optional step).

366 14. Place the RNeasy mini spin column in a new $1.5 \mathrm{~mL}$ collection tube and add $30--50 \mu \mathrm{L}$

367 RNase-free water directly to the spin column membrane. Close the lid, and centrifuge at $\geq 8,000$

$368 x g$ for 1 min to elute the RNA.

369 15. If the expected RNA yield is $>30 \mu \mathrm{g}$, repeat step 14 using another $30--50 \mu \mathrm{L}$ RNase-free

370 water, or the elute from step 14 (if a high RNA concentration is required). Reuse the collection

371 tube from step 14. Note: if the elute from step 14 is used, the RNA yield might be 15--\% lower

372 than using a second volume of RNase-free water but the final RNA concentration will be higher

373 (see Note 14).

374 16. Quantify the extracted RNA and evaluate its quality using a NanoDrop spectrophotometer or

375 a RNA-integrity gel. Either use the eluted RNA directly in following steps (RT-PCR and QPCR)

376 or store the eluted RNA at $-80^{\circ} \mathrm{C}$ for later analysis.

378 3.7.2. $c D N A$ Synthesis

379 Use $50 \mu \mathrm{L}$ from each sample obtained for total RNA to single-stranded cDNA reverse

380 transcription(RT). We follow the recommendations from the High Capacity cDNA RT kit (PN

381 4368814, Applied Biosystems).

382 1. Place the $2 \times$ RT master mix on ice and mix gently.

383 2. Pipette $25 \mu \mathrm{L}$ of $2 \times \mathrm{RT}$ master mix into each well of an individual tube (see Note 15).

384 3. Pipette $25 \mu \mathrm{L}$ of RNA sample into each well, pipetting up and down two times to mix (see 385 Note 16). 
4. Seal the tubes and briefly centrifuge them to spin down the contents and to eliminate any air bubbles.

388 5. Place the plate or tubes on ice until you are ready to load them into the thermal cycler.

6. Program the thermal cycler conditions with the following parameter steps: (i) step 1: $25^{\circ} \mathrm{C}$ for indefinite time.

392 7. Set the reaction volume to $20 \mu \mathrm{L}$.

393 8. Load the reactions into the thermal cycler and start the reverse transcription run.

394 9. Quantify the synthetized cDNA and evaluate its quality using a NanoDrop spectrophotometer

395 or cDNA integrity gel.

396 3.7.3. PCR Analysis

397 Use a $50 \mu \mathrm{L}$ reaction per sample to obtain the PCR products. We follow the recommendations

398 from FastStart PCR Master (04710436001; Roche).

399 1. Prepare the microplates for PCR according to the instrument instructions.

400 2. Thaw the solutions and briefly spin the vials in a microcentrifuge before opening.

401 3. Mix the solutions by pipetting them up and down gently and store them on ice.

402 4. Prepare $10 \times$ concentration solutions of the PCR primers (see Table 3 )

403 5. Prepare a PCR mix for the number of reactions to be run plus one additional reaction. The PCR 404 mix contains the following products for each reaction in the following order: $25 \mu \mathrm{L} 2 \times$ master

405 mix, $5 \mu \mathrm{L}$ forward primer $(3 \mu \mathrm{M}), 5 \mu \mathrm{L}$ reverse primer $(3 \mu \mathrm{M})$, and $10 \mu \mathrm{L}$ PCR-grade water.

406 6. Mix the solution by pipetting it up and down (do not vortex).

407 7. Transfer $45 \mu \mathrm{L}$ PCR mix into each reaction well of the PCR microplate.

408 8. Add $5 \mu \mathrm{L}$ of template DNA (up to $100 \mathrm{ng}$ cDNA) into each reaction well.

409 9. Prepare the microplate for the PCR reaction according to the instrument's instructions.

410 10. Program the thermal cycler conditions with following steps: (i) step 1: 1 cycle at $95^{\circ} \mathrm{C}$ for 4

$411 \mathrm{~min}$; (ii) step 2: 30 to 40 cycles at $95^{\circ} \mathrm{C}$ for $30 \mathrm{~s}$, and $45--65^{\circ} \mathrm{C}$ for $30 \mathrm{~s}$, and $72^{\circ} \mathrm{C}$ for $45--180 \mathrm{~s}$;

412 (iii) step 3: 1 cycle at $72^{\circ} \mathrm{C}$ for $7 \mathrm{~min}$; (iv) step $4: 4^{\circ} \mathrm{C}$ for an indefinite time.

413 7. Set the reaction volume to $50 \mu \mathrm{L}$.

414 8. Load the microplate into the thermal cycler and start the PCR reaction.

415 The results can be observed in the electrophoresis gels on Fig. 4B and Fig. 4C.

416 3.7.4. QPCR Analysis

417 1. Completely thaw the Power SYBR Green PCR Master Mix and gently mix the reagents. 
2. In polypropylene tubes, prepare the PCR reagent mix for the desired number of PCR

reactions. Each $20 \mu \mathrm{L}$ PCR reaction contains $10 \mu \mathrm{L}$ of the PCR Master Mix, 50--300 nM from each primer, $100 \mathrm{ng}$ template, and a variable quantity of nuclease-free water (see Note 17).

3. Mix gently (do not vortex) and centrifuge briefly.

4. Prepare the microplate for the QPCR reactions according to instrument's instructions.

5. Program the thermal cycler conditions with the following steps: (i) step 1: 1 cycle at $95^{\circ} \mathrm{C}$ for $4 \mathrm{~min}$; (ii) step 2: 30 to 40 cycles at $95^{\circ} \mathrm{C}$ for $30 \mathrm{~s}, 45--65^{\circ} \mathrm{C}$ for $30 \mathrm{~s}$, and $72^{\circ} \mathrm{C}$ for $45--180 \mathrm{~s}$; (iii) step 3: 1 cycle at $72{ }^{\circ} \mathrm{C}$ for $7 \mathrm{~min}$; (iv) step 4 at $4{ }^{\circ} \mathrm{C}$ for an indefinite time.

6. Set the rest of the thermal cycler parameters (e.g., volume $=20 \mu \mathrm{L}$ ) following instrument user's manual to configure the plate documentation details.

428 7. Load the microplate into the thermal cycler and start the PCR reaction.

429 8. Analyze and export the results using a spreadsheet program with statistical features.

430 9. Calculate the average cycle time, the standard deviation, and the coefficient of variation for 431 each group of replicates of any sample. Remove outlier points ( $\mathrm{Ct}>0.3 \times$ standard deviation).

432 10. Apply the $\Delta \Delta \mathrm{Ct}$ method to obtain "fold changes" as desired output (20). The internal control 433 selected is $\beta-2$ microglobulin gene.

\section{3.8. Telomerase activity assay}

435 Telomerase activity is assayed using telomeric repeat amplification protocol using the Trapeze

436 Kit (Chemicon) and according to the manufacturer's protocol but with some modifications.

\section{3.8.1 Sample Preparation}

438 1. For stem cell analysis, collect $30--100$ colonies. Pellet cells at $400 \times g$ for 5 min at $4^{\circ} \mathrm{C}$. We

439 highly recommend that the positive and negative controls provided with the kit and a negative 440 control (a differentiated cell line and/or heat inactivated immortal/stem cells) be used.

441 2. Wash cell pellet with sterile $\mathrm{Ca}^{2+}$ and $\mathrm{Mg}^{2+}$ free PBS for $5 \mathrm{~min}$ at $400 \times g$ at $4^{\circ} \mathrm{C}$.

442 3. Resuspended the cell pellet with 5--20 $\mu$ L CHAPS lysis buffer (Thermo Scientific) for stem 443 cell colonies.

444 4. Place on ice for $30 \mathrm{~min}$.

445 5. Pellet cells at high speed (12,000 rpm) at $4^{\circ} \mathrm{C}$ for $20 \mathrm{~min}$.

446 6. Transfer the supernatant to a new tube. At this point the supernatants are kept at $-80^{\circ} \mathrm{C}$ and can 447 be stored for up to one year to be used for telomerase detection. 
2. Heat inactivated negative controls must be subjected to $85^{\circ} \mathrm{C}$ for ten min. Then use the same

452

453

454

455

456

457

458

459

460

461

462

463

464

465

466

467

468

469

470

471

472

473

474

475

476

477

478

479

480

481

2--4 $\mu \mathrm{L}$ volume for the PCR reactions.

3. Prepare a master mix containing all these components except the templates, all the reagents are provided by the kit except Taq polymerase:

- 10× TRAP Reaction buffer $5 \mu \mathrm{L}$

- $50 \times$ dNTP mix

$1 \mu \mathrm{L}$

- TS primer

$1 \mu \mathrm{L}$

- $\quad$ TRAP primer mix

$1 \mu \mathrm{L}$

- Taq polymerase $(5 \mathrm{U} / \mu \mathrm{L}) \quad 0.4 \mu \mathrm{L}$

- $\mathrm{dH}_{2} \mathrm{O}$

$29.5 \mu \mathrm{L}$

- Template

$2 \mu \mathrm{L}$

4. PCR program

- 1 cycle:

$30^{\circ} \mathrm{C} 30 \mathrm{~min}$

- 30--33 cycles:

$94^{\circ} \mathrm{C} 30 \mathrm{~s}$

$59^{\circ} \mathrm{C} 30 \mathrm{~s}$

\subsubsection{Separation by Electrophoresis}

1. For sample electrophoresis, use a 10--15 $\mu 1$ PCR reaction with a 2--5 $\mu 1$ loading buffer 10x (BioRad).

2. Load a nondenaturing 10--20\% polyacrylamide gel (we use 15\% precasted gels from BioRad).

3. Run the gel in TBE 0.5X until both color bands are out of the gel.

4. Prepare the SYBR green solution $(1 / 10,000)$ in TBE $1 X$.

5. Stain the gel for $15--20$ min in the dark.

6. Visualize the bands in a transilluminator (with the same wavelength as the ethidium bromide). The results for telomerase activity are presented in Fig. 4D.

\section{Notes}

1. Conditioned media can be prepared using foreskin fibroblasts between passages 11--18, but in order to maintain the quality, we recommend that cells between passages 11 to 16 be used.

2. Cell counting: take $20 \mu \mathrm{L}$ of cell suspension and dilute it with $70 \mu \mathrm{L}$ of culture medium. Add $10 \mu \mathrm{L}$ of Trypan Blue solution (Sigma), mix, and incubate for $1 \mathrm{~min}$ before counting viable (round, clear cells) and nonviable (blue) cells using a Neubauer haemocytometer and plate $6 \times 10^{6}$ 

than $75 \%$ of cells should be viable.

3. Before using of conditioned TESR 1 medium, add $100 \mathrm{ng} / \mathrm{mL}$ of bFGF and $50 \mathrm{ng} / \mathrm{mL}$ of TGF$\beta 1$. Conditioned medium can be kept at $+4^{\circ} \mathrm{C}$ for 1 week or stored at $-80^{\circ} \mathrm{C}$ for 6 months.

4. No differences between frozen and fresh conditioned media have been observed.

5. Lysis buffer preparation. The following is an example for $250 \mathrm{~mL}$ :

6. TEM inclusion procedure: Glutaraldehyde is carcinogenic by inhalation, it is important to manipulate it in a fume hood. During the $37^{\circ} \mathrm{C}$ incubation it is very important to avoid inhaling these fumes, keeping the culture plates inside a petri dish in the special stove. Osmium is carcinogenic and toxic by inhalation and contact and so double gloves and a mask should be worn, in addition to working under fume hood. Uranyl acetate is carcinogenic and radioactive. Manipulation must be performed in an adequate installation under fume hood using double gloves and a mask. Given their toxicity, those residues need to be manipulated and discarded properly.

510 8. Do not use until the solution reaches room temperature and adjust the $\mathrm{pH}$ if necessary.

511 9. We have also performed this process by incubating with ice in the orbital shaker for 2.5 hours.

512 10. When planning to do TEM analysis, the seeding of hFFs, the cell lysis and subsequent 513 pluripotent cell seeding needs to be done on Permanox ${ }^{\circledR}$ chambers.

514 11. At this point, the plates can be maintained for several days at $4^{\circ} \mathrm{C}$ by adding sodium azide. 
515 12. hESCs were cultured and maintained as previously described (21). Cells were passaged

516 mechanically and re-plated on ECM-coated plates.

517 13. The optimal size of hESCs before the splitting procedure is when the colonies completely

518 cover the magnification field (x10).

519 14. If you use the elution obtained in step 10, the quantity of RNA obtained may be 15--30\% less

520 than using RNase-free water.

521 15. The kit reagents must always be thawed on ice.

522 16. Use up to $5 \mu \mathrm{g}$ of total RNA per $50 \mu \mathrm{L}$ RT reaction.

523 17. Include an extra volume to account for pipetting losses.

\section{Acknowledgements:}

525 The authors would like to thank Dr. Deborah Burks, Dr. Sonia Prado, Dr. X. Chen Xiong, Mrs.

526 Vanessa Blanca, Dr. Angel Ayuso-Sacido, and Petra Stojkovic for their support. This work was

527 supported by funds for research in the field of Regenerative Medicine from the Regional

528 Government Health Department (Generalitat Valenciana); the Instituto Carlos III belongs to the

529 Spanish Ministry of Health and Consumer Affairs. Drs. Carmen Escobedo-Lucea and Andres

530 Sanz-Garcia are financed by Academy of Finland projects as follows: No. 273689 (Research

531 Fellow), No. 266486 (FINSKIN), No. 276371 (VATURP), and No. 278153 (mobility grant). 


\section{Figure Captions}

A
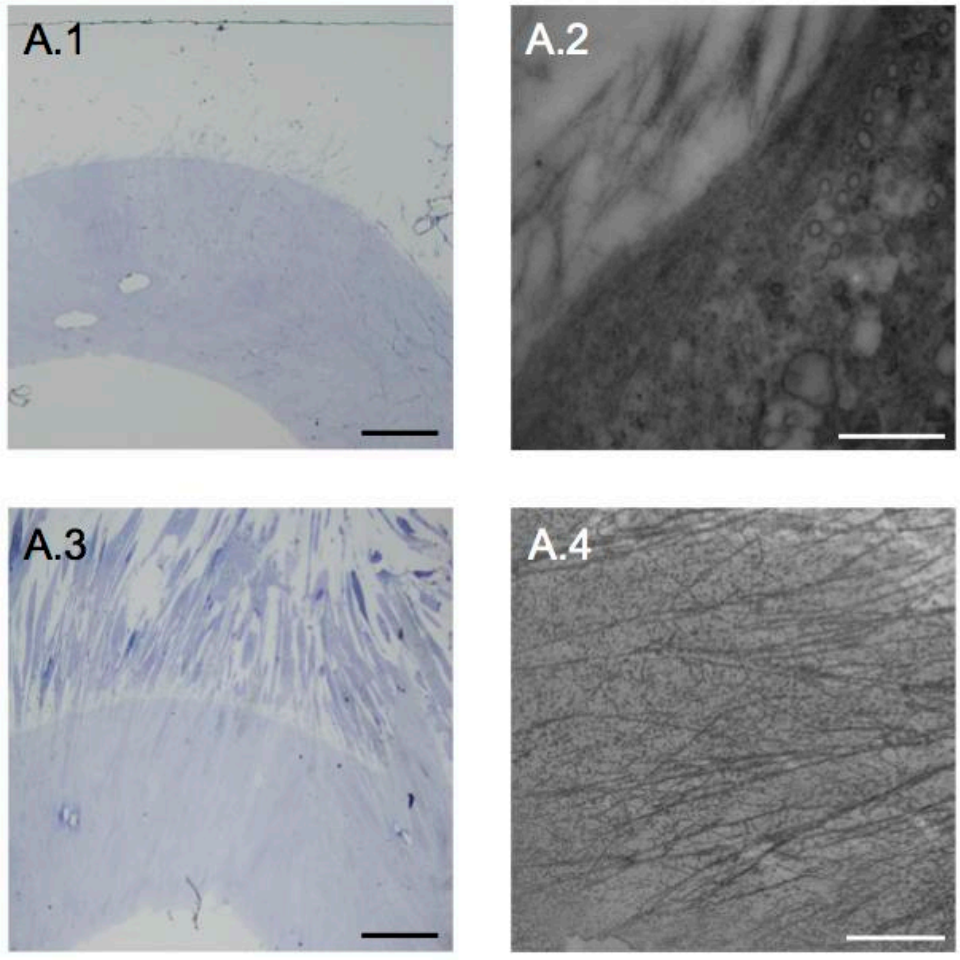

B
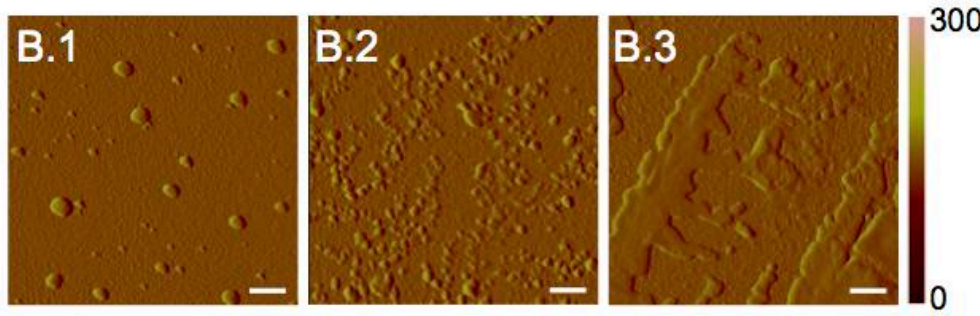

535 Fig. 1. Transmission electron microscopy (TEM) and atomic force microscopy (AFM) of the

$536 \mathrm{hffECM}$ after the extraction to evaluate structural integrity and roughness. (A) Ultrastructural

537 analysis of the efficiency of the extraction protocol using TEM. Plates of lysed cultures and their

538 respective controls with intact foreskin fibroblasts were fixed and processed for TEM

539 ultrastructural analysis. Human foreskin fibroblasts (hFFs) were maintained for the indicated

540 times and then subjected to hypotonic lysis. (A.1 and A.3) Semi-thin sections were prepared from

541 control and lysed cultures and were stained with toluidine blue. (A.2) Representative TEM image

542 of intact hFF control cells after 7 days in culture. (A.4) Representative TEM image of lysed

543 culture plate after 7 days in culture. Scale bars, $200 \mu \mathrm{m}$ (A.1 and A.3), $1 \mu \mathrm{m}$ (A.2), 500nm (A.4).

544 (B) AFM analysis of ECM conformation on glass surfaces. The images show the amplitude mode

545 with the same scale. (B.1) The smallest roughness corresponds to fibronectin that was used as 
547 roughness is significantly lower on day 1 (B.2) than after hFFs culture on day 2 (B.3). Scale bars

$548250 \mathrm{~nm}$ (Figures 1.A.1 and 1.A.3 reproduced from (12) with permission from Springer).
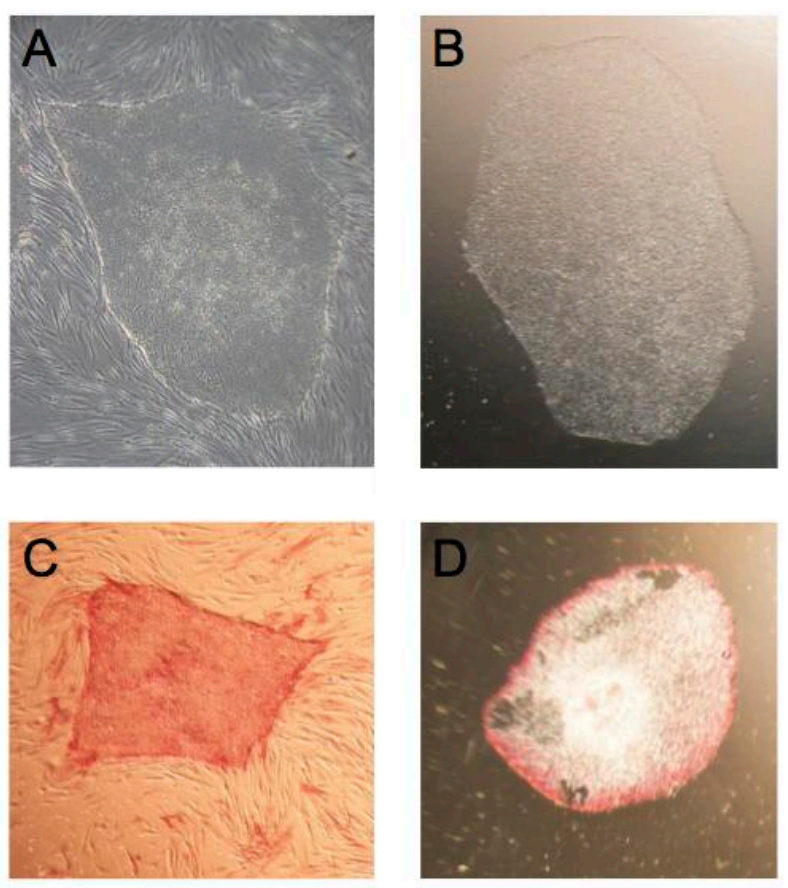

557 Fig. 2. (A and B) Morphology of undifferentiated hESCs grown for 11 passages over feeder cells

558 and on plastic coated with hffECM using conditioned media respectively. (C and D) Images

559 showing alkaline phosphatase activity in both feeder and hffECM conditions, indicating

560 maintenance of pluripotency. Images were obtained using Zeiss Axiovert 200M microscope

561 (magnifications $\times 100$ ). 

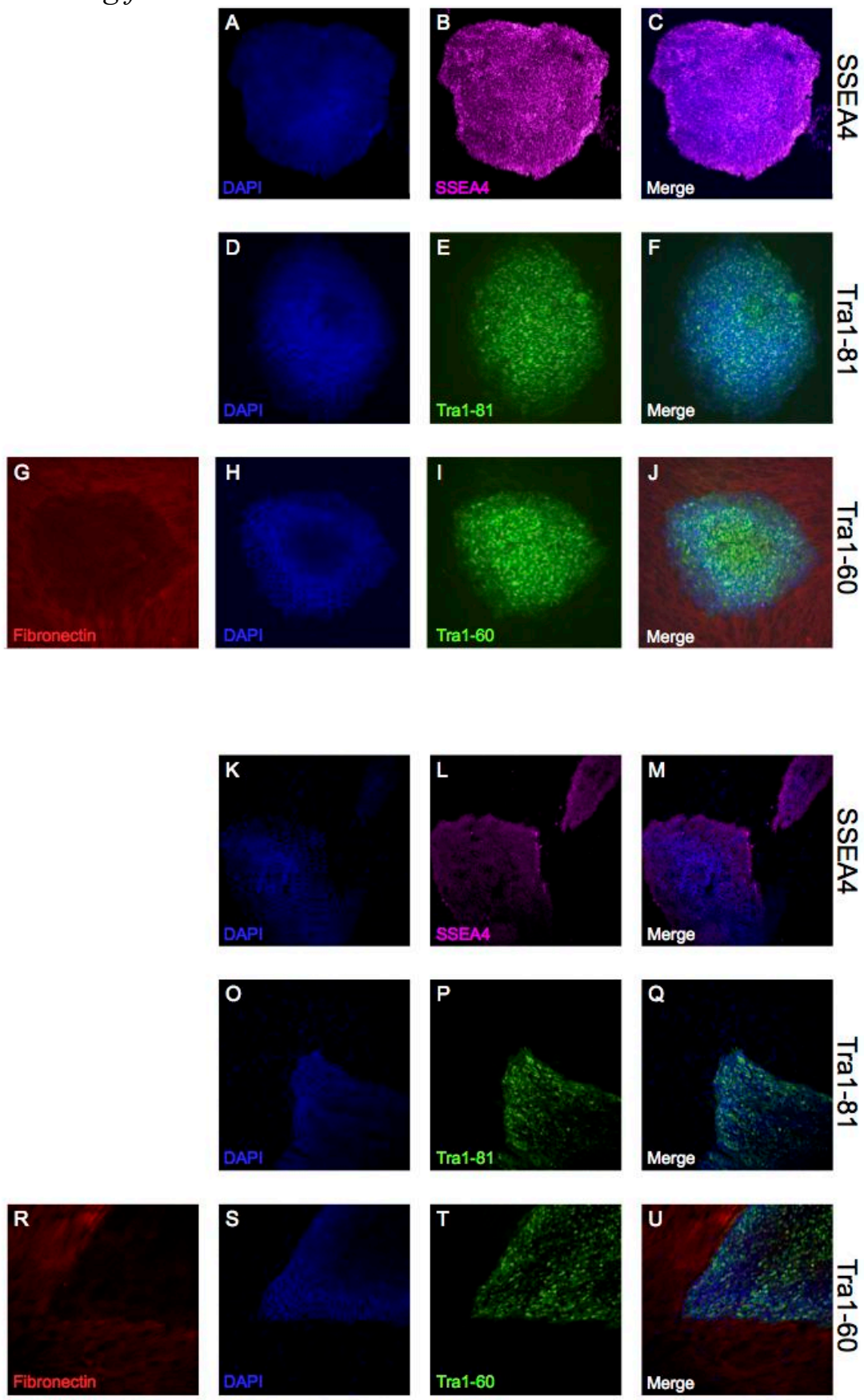

Fig. 3. Morphology and cell surface markers of undifferentiated hESC grown for 11 passages on

565 plastic dishes coated with hffECM derived from human fibroblasts and in the presence of

566 conditioned medium. Note round and compacted hESC colonies. The presence of SSEA4 (A--C,

567 magenta), Tra1-81 (D--F, green), Tra1-60 (H--J, green), pluripotency markers were observed.

568 Note the presence of specific fibronectin staining (G--J and $\mathbf{R}-\mathbf{U})$.

569 Morphology and cell surface markers of undifferentiated hESCs grown for 11 passages over hFFs

570 feeder. The presence of SSEA4 (K--M, magenta), TRA-1-81 (O--K, green), TRA-1-60 (S--U,

571 green), pluripotency markers were observed. Note the presence of specific fibronectin staining (G

572 and $\mathbf{J})$. Images were obtained using confocal microscope (10× magnifications). 
A

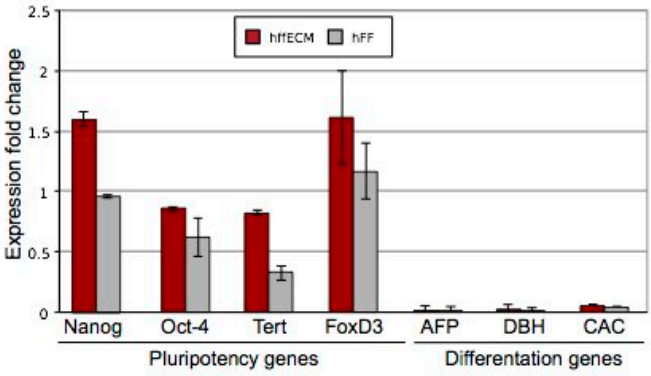

B

C
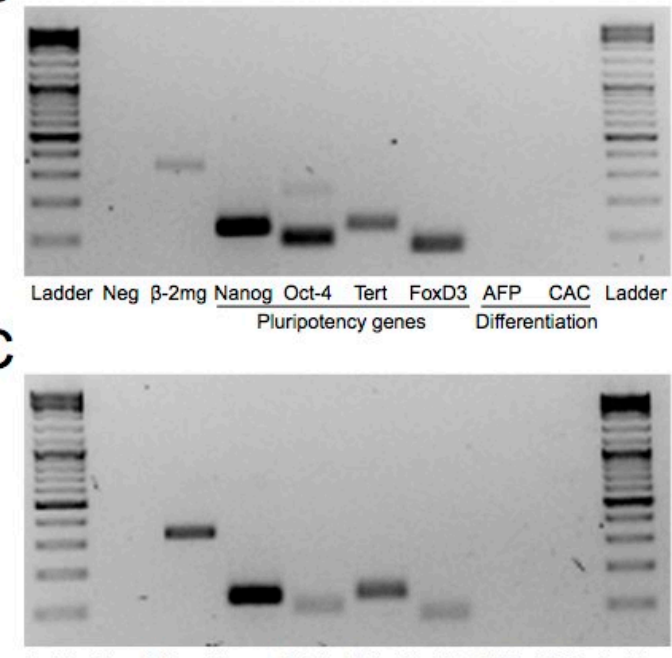

Ladder Neg 3 -2mg Nanog Oct-4 Tert FoxD3 AFP CAC Ladder
D

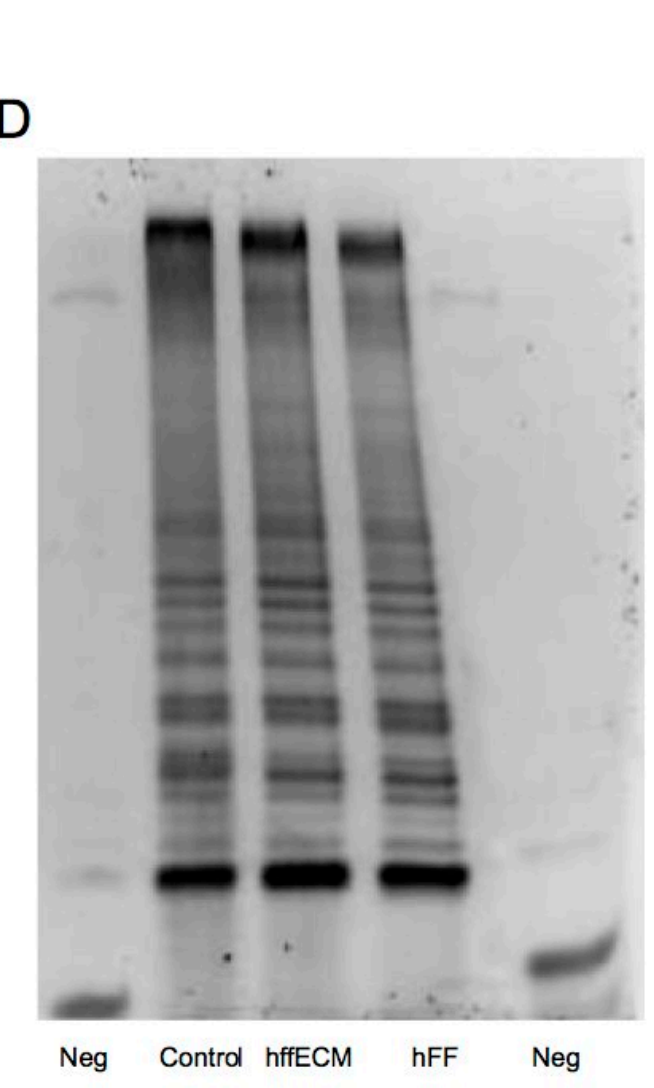

Fig. 4. Analysis of specific molecular hESC markers and telomerase activity. hESCs were grown on hffECM and in the presence of conditioned medium for 11 passages. Controls over foreskin feeder were also and grown at the same time. (A) QPCR comparing expression of pluripotency and differentiation genes in cells maintained on hffECM and hFF. The expression of characteristic pluripotent markers is higher in the cells maintained on hffECM than on hFF. This indicates that our system is highly selective and only cells with the best quality are able to adapt and survive. No expression of differentiation markers (AFP, DBH and CAC) was detected. (B and C) Cells maintained on hffECM and foreskin feeders respectively. Line 1 and 10: Ladders with $1 \mathrm{~Kb} ; 2$. Corresponds to negative control; 3. Housekeeping gene $3-2$ microglobulin. Cells express all the typical hESC markers 4. Nanog; 5. Oct-4; 6. Tert; 7. FoxD3. After 11 passages on ECM the cells were negative for differentiation markers AFP and CAC (lines 8 and 9, respectively. (D) Colonies retained telomerase activity after 11 passages on hffECM (line 3).

587 Line 4 corresponds to their H9 counterparts maintained 11 passages over foreskin feeder cells.

588 Line 1 and 6 are negative controls, and the line 2 the positive control. 


\section{Table}

Table 1. List of primary antibodies

593

594

\begin{tabular}{|l|c|c|c|c|}
\hline Primary antibody & Isotype & Working dilution & Catalogue number & Provider \\
\hline SSEA4 & IgG3 & $1: 100$ & MAB 4304 & Chemicon \\
\hline Tra1-81 & IgM & $1: 100$ & MAB 4381 & Chemicon \\
\hline Tra1-60 & IgM & $1: 100$ & MAB 4360 & Chemicon \\
\hline Fibronectin & IgG1 & $1: 100$ & F0916 & Sigma \\
\hline
\end{tabular}


605 Table 2. List of secondary antibodies

606

607

\begin{tabular}{|l|c|c|c|}
\hline Secondary antibody & Working dilution & Catalogue number & Provider \\
\hline Alexa Fluor goat against IgG & $1: 500$ & $\mathrm{~A} 11029$ & Invitrogen \\
\hline Alexa Fluor against IgM & $1: 500$ & $\mathrm{~A} 21042$ & Invitrogen \\
\hline Alexa Fluor against IgG1 & $1: 500$ & $\mathrm{~A} 21124$ & Invitrogen \\
\hline
\end{tabular}

608

609

610

611 
612

613 Table 3. List of primers and conditions used for both RT-PCR and qPCR

614

615

\begin{tabular}{|c|c|c|c|c|}
\hline Gene Name & Primer Sequences & $\begin{array}{c}\text { Annealing } \\
\text { Temperature }\left({ }^{\circ} \mathrm{C}\right)\end{array}$ & Size (bp) & Detection \\
\hline \multicolumn{5}{|c|}{ Housekeeping gene } \\
\hline ß2-microglobulin & $\begin{array}{l}\text { F: CTCGCGCTACTCTCTCTTTCTG } \\
\text { R: GCTTACATGTCTCGATCCCACT }\end{array}$ & 55 & 335 & $\begin{array}{c}\text { RT-PCR } \\
\text { QPCR }\end{array}$ \\
\hline \multicolumn{5}{|c|}{$\begin{array}{l}\text { Pluripotency assay genes } \\
\end{array}$} \\
\hline Nanog & $\begin{array}{l}\text { F: GGTGGCAGAAAAACAACTGG } \\
\text { R: }\end{array}$ & 60 & 235 & RT-PCR \\
\hline Nanog & $\begin{array}{r}\text { F: AATGGTGTGACGCAGAAGG } \\
\text { R: ACTGGATGTTCTGGGTCTGG }\end{array}$ & 60 & & QPCR \\
\hline Oct-4 & $\begin{array}{l}\mathrm{F}: \text { cctgtctccgtcaccactct } \\
\mathrm{R}: \text { CAAAAACCCTGGCACAAACT }\end{array}$ & 60 & 128 & $\begin{array}{c}\text { RT-PCR } \\
\text { QPCR }\end{array}$ \\
\hline FoxD3 & $\begin{array}{c}\text { F: CAGAGCCCGCAGAAGAAG } \\
\text { R: CGAAGCAGTCGTTGAGTGAG }\end{array}$ & 60 & 133 & RT-PCR \\
\hline FoxD3 & $\begin{array}{l}\text { F: GCCCAAGAACAGCCTAGTGA } \\
\text { R: GGGTCCAGGGTCCAGTAGTT }\end{array}$ & & 254 & QPCR \\
\hline Tert & $\begin{array}{c}\text { F: GACCTCCATCAGAGCCAGTC } \\
\text { R: CGCAAGACCCCAAAGAGTT }\end{array}$ & 60 & 84 & RT-PCR \\
\hline Tert & $\begin{array}{l}\text { F: GCGTTTGGTGGATGATTTCT } \\
\text { R: AGCTGGAGTAGTCGCTCTGC }\end{array}$ & 60 & 254 & QPCR \\
\hline \multicolumn{5}{|c|}{ Differentiation assay genes } \\
\hline AFP & $\begin{array}{l}\text { F: TGCGTTTCTCGTTGCTTACA } \\
\text { R: GCTGCCATTTTTCTGGTGAT }\end{array}$ & 60 & 81 & RT-PCR \\
\hline AFP & $\begin{array}{l}\text { F: Acacaaaagcccactccag } \\
\text { R: ggtgcatacaggaagggatg }\end{array}$ & 60 & 147 & QPCR \\
\hline DBH & $\begin{array}{l}\mathrm{F}: \text { tgactgggagaaaggtggtc } \\
\mathrm{R}: \text { tacgtgcaggaggtgatgag }\end{array}$ & 60 & 160 & QPCR \\
\hline CAC & $\begin{array}{l}\mathrm{F}: \text { tgctgatcgtatgcagaagg } \\
\mathrm{R}: \text { gctggaaggtggacagagag }\end{array}$ & 60 & 135 & $\begin{array}{c}\text { RT-PCR } \\
\text { QPCR }\end{array}$ \\
\hline
\end{tabular}

616

617

618

619 
621 1. Takahashi K, Okita K, Nakagawa M et al. (2007) Induction of pluripotent stem cells from fibroblast cultures. Nat Protoc 2 (12), 3081--3089

623 2. Takahashi K, Tanabe K, Ohnuki M et al. (2007) Induction of Pluripotent Stem Cells from Adult Human Fibroblasts by Defined Factors. Cell 131 (5), 861--872

625 3. Klimanskaya I, Chung Y, Meisner L et al. (2005) Human embryonic stem cells derived without feeder cells. Lancet 7 (13), 1636--1641

4. Xu C, Inokuma M, Denham J et al. (2001) Feeder-free growth of undifferentiated human embryonic stem cells. Nat Biotechnol 19 (10), 971--974

629 5. Cyranoski D (2014) Next-generation stem cells cleared for human trial. Nature,

630 6. Schwartz SD, Regillo CD, Lam BL et al. (2014) Human embryonic stem cell-derived retinal pigment epithelium in patients with age-related macular degeneration and Stargardt's macular dystrophy: follow-up of two open-label phase 1/2 studies. The Lancet, 7. Martin MJ, Muotri A, Gage F et al. (2005) Human embryonic stem cells express an immunogenic nonhuman sialic acid. Nature Medicine 11, 228--232 8. Kagami S, Kondo S, Löster K et al. (1998) Collagen type I modulates the platelet-derived growth factor (PDGF) regulation of the growth and expression of beta1 integrins by rat mesangial cells. Biochem Biophys Res Commun 252 (3), 728--732

638 9. Sjaastad MD, Nelson WJ (1997) Integrin-mediated calcium signaling and regulation of cell 639 adhesion by intracellular calcium. Bioessays 19, 47--55

640 10. Schuppan D, Cramer T, Bauer M et al. (1998) Hepatocytes as a source of collagen type XVIII endostatin. Lancet 352, 879--880

mension. Science 294 (5547), 1708--1712

644 12. Escobedo-Lucea C, Ayuso-Sacido A, Xiong C et al. (2012) Development of a human extracellular matrix for applications related with stem cells and tissue engineering. Stem Cell Rev 8 (1), 170--183 decellularised porcine aortic valves: matrix changes due to different decellularisation methods. Eur J Cardiothorac Surg 27 (4), 566--571 14. Escobedo-Lucea C, Stojkovic M (2010) Growth of human embryonic stem cells using derivates of human fibroblasts. Methods Mol Biol 584, 55--69 isolation and expansion of human adipose stem cells for clinical uses. PLoS One 8 (7), e67870 16. Prado-Lopez S, Conesa A, Arminan A et al. (2010) Hypoxia promotes efficient differentiation of human embryonic stem cells to functional endothelium. Stem Cells 28 (3), 407-418

17. Ludwig TE, Levenstein ME, Jones JM et al. (2006) Derivation of human embryonic stem cells in defined conditions. Nat Biotech 24 (2), 185--187 18. Werb Z, Chin JR (1998) Extracellular Matrix Remodeling during Morphogenesisa. Ann N Y Acad Sci 857 (1), 110--118 19. Thomson JA, Itskovitz-Eldor J, Shapiro SS et al. (1998) Embryonic stem cell lines derived from human blastocysts. Science 6 (282), 1145--1147

663 20. Livak KJ, Schmittgen TD (2001) Analysis of relative gene expression data using real-time quantitative PCR and the $2^{\wedge}[$-delta delta C(T)] Method. Methods 25 (4), 402--408 
669

670

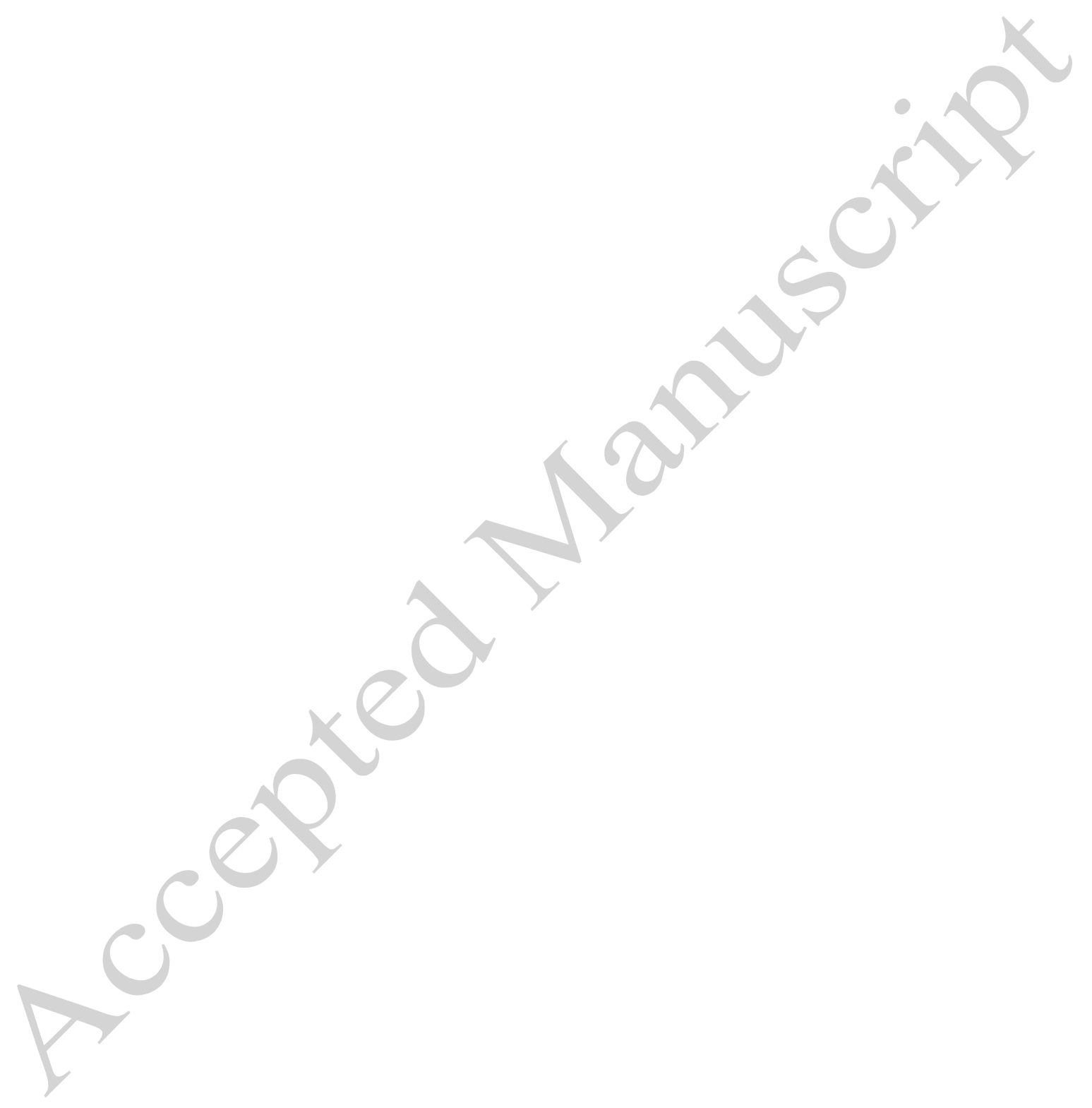

